\title{
Psicologia e Saúde: A Terapia Comunitária como Instrumento de Sensibilização para o Trabalho com Comunidades na Formação do Psicólogo
}

Psychology and Health: Community Therapy as a Tool of Awareness for the Work with

Communities in Psychology Formation

Psicología y Salud: La Terapia Comunitaria como Instrumento de Sensibilización para el Trabajo con Comunidades en La Formación del Psicólogo

Marta Fuentes-Rojas

Universidade Estadual de Campinas
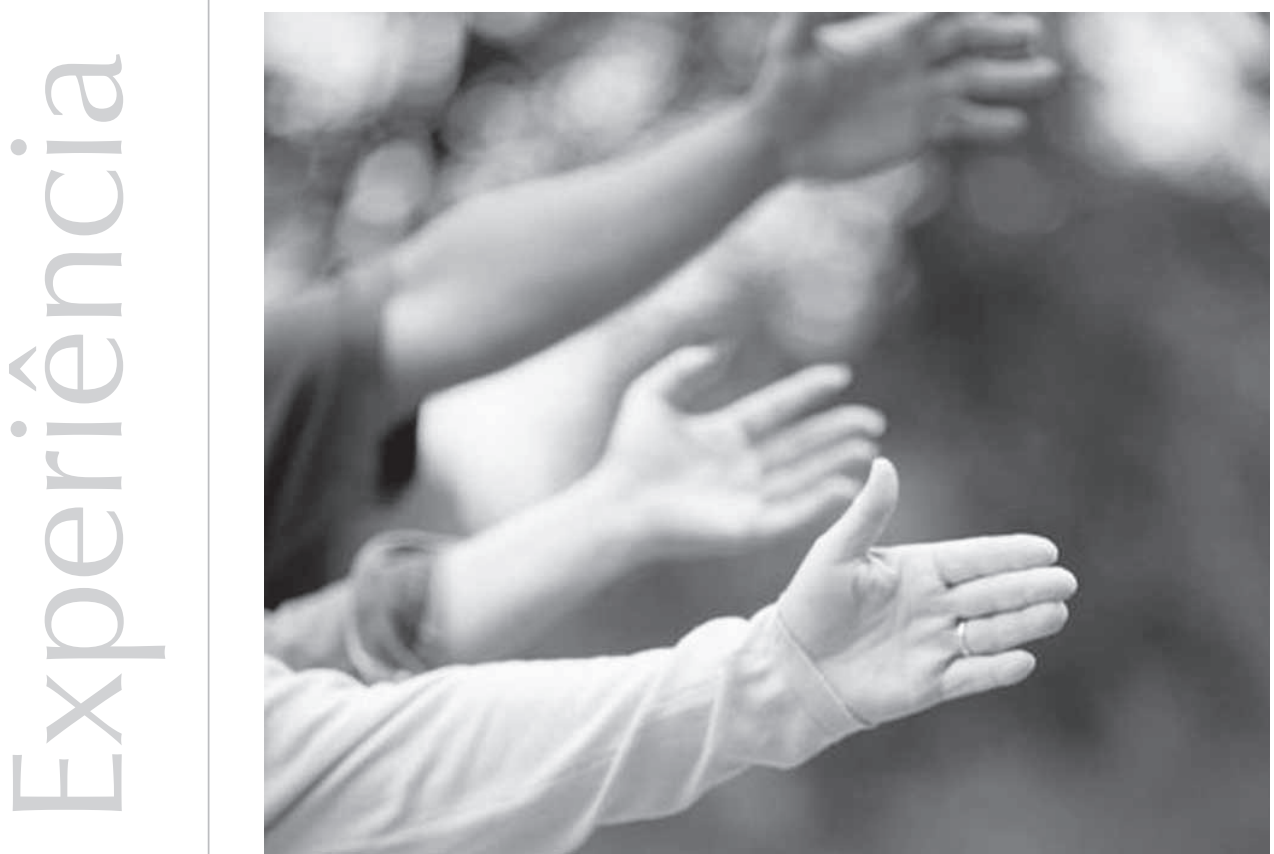
Resumo: A participação do psicólogo na atenção primária implica uma preparação para esse campo de trabalho. A terapia comunitária vem de encontro a essa proposta oferecendo ao psicólogo um instrumento de trabalho de promoção e prevenção em saúde mental. Este trabalho corresponde ao relato de experiência da autora no curso de Psicologia, sendo que, na reformulação do currículo desse curso, foi possível incluir a terapia comunitária a partir do 2 o semestre de 2005, com a finalidade de oferecer aos alunos(as) uma visão diferente em relação à promoção e à prevenção em saúde nas comunidades. Foi possível observar que os alunos(as) desenvolveram uma postura crítica em relação ao uso das técnicas e de sua contribuição para o desenvolvimento das comunidades, sensibilizaram-se com a sua dor e o seu sofrimento, ressignificando, assim, o próprio conceito de sofrimento. Do atendimento clínico/individual, avançaram na direção de um trabalho mais coletivo e comunitário.

Palavras-chave: Psicologia comunitária. Ética profissional. Promoção da saúde. Formação do psicólogo.

\begin{abstract}
The involvement of psychologists in primary attention includes a preparation for this field of work. The community therapy takes part in this proposal offering psychologists a tool for the promotion and prevention in mental health. This paper is the report of the author's experience in a university course of psychology, and the redevelopment of the course curriculum included community therapy since the $2^{\text {nd }}$ semester of 2005, aiming to offer students a different view of health promotion and prevention in communities. It was observed that the students began to present a critical posture in relation to the use of techniques and to their contribution to the development of communities, for they became aware of their pain and suffering, re-signifying their own concept of suffering. From the clinical/individual care, they moved on to a more collective and communitarian work.
\end{abstract}

Keywords: Community psychology. Ethics professional. Health promtion. Psychologist education.

Resumen: La participación del psicólogo en la atención primaria implica una preparación para ese campo de trabajo. La terapia comunitaria viene de encuentro a esa propuesta ofreciendo al psicólogo un instrumento de trabajo de promoción y prevención en salud mental. Este trabajo corresponde al relato de experiencia de la autora en el curso de Psicología, siendo que, en la reformulación del currículo de ese curso, fue posible incluir la terapia comunitaria a partir del $2^{\circ}$ semestre de 2005 , con la finalidad de ofrecer a los alumnos(as) una visión diferente en relación a la promoción y a la prevención en salud en las comunidades. Fue posible observar que los alumnos(as) desarrollaron una postura crítica en relación al uso de las técnicas y de su contribución para el desarrollo de las comunidades, se sensibilizaron con su dolor y su sufrimiento, dando un nuevo significado entonces al propio concepto de sufrimiento. De la atención clínico/individual, avanzaron en dirección a un trabajo más colectivo y comunitario.

Palabras clave: Psicología comunitaria. Etica profesional. Promoción de la salud. Formación del psicólogo.

Este artigo descreve a experiência de três anos como docente da disciplina Terapia Comunitária, dentro do eixo Práticas Psicológicas I, no curso de Psicologia, e o impacto desse novo conteúdo na formação dos estudantes de Psicologia. Relatar o desenvolvimento dessa disciplina torna-se importante pelas suas características e por marcar a presença e a valorização de temas relacionados com a saúde coletiva dentro do currículo. Para tanto, os objetivos propostos por essa disciplina foram apresentar, discutir e refletir sobre a participação do psicólogo na atenção primária, trazer conteúdos, conceitos e práticas relacionadas com a promoção e a prevenção em saúde, além de incentivar, na formação do psicólogo, o interesse pelo trabalho com comunidades e o contato direto com esse tipo de trabalho, utilizando como instrumento de sensibilização a terapia comunitária.

\section{A Psicologia e a saúde coletiva}

A Psicologia é uma profissão relativamente nova. Foi regulamentada no Brasil através da Lei $n^{\circ} 4.119$, de 27 de agosto de 1962. No início da década de 70 , a profissão de psicólogo começou a se estabelecer e foi criado o Conselho Federal de Psicologia, apesar de a categoria ter sido duramente atacada pelos médicos. No final dessa década, ocorre mudança na política de saúde mental no Brasil, influenciada pela psiquiatria 
comunitária dos Estados Unidos. A crise do modelo médico e a dificuldade da psiquiatria para modificar o quadro assistencial no nível público geraram a necessidade de instituir formas de trabalho multiprofissionais, das quais o profissional da Psicologia também pôde fazer parte (Barros \& Yamamoto, 2002).

Para os autores acima, o psicólogo entrou no serviço público em decorrência da crise econômica, que provocou a diminuição da demanda no campo privado, da crítica feita à psicologia clínica tradicional, por não apresentar uma participação social relevante e do surgimento de práticas alternativas socialmente aceitas que, de alguma forma, puderam absorver a demanda social.

Ao mesmo tempo, os hospitais, ambulatórios e centros de saúde abriram-se para a construção de novos espaços de atuação multiprofissional, promovendo uma inserção social mais significativa por parte do psicólogo. No entanto, o impacto desses novos espaços não tem sido suficientemente forte a ponto de influenciar as propostas de formação de psicólogos e objetivar um perfil diferenciado e de acordo com as demandas da saúde pública.

O que se percebe é a manutenção do perfil tradicional, identificado com o modelo de intervenção clínica, dentro da área de humanas, fortalecendo assim a identidade do profissional da Psicologia, que, segundo Nader (1990 citado por Barros \& Yamamoto, 2002), se constrói como resultado da articulação entre a aplicação de determinado conteúdo teórico-técnico e as representações sociais do psicólogo e da Psicologia.

Em relação ao campo de saber da Psicologia e de sua inserção na saúde, Spink (1992) afirma que a Psicologia entrou nessa área pela sua experiência clínica e pela sua contribuição no debate sobre os aspectos psicológicos do processo saúde/doença, especificamente na área da saúde mental. Essa inserção ofereceu condições que permitiram estruturar um novo campo de saber, a área da saúde, e ampliar o número de profissionais que, aproveitando o saber acumulado, buscaram contextualizar sua prática na área da saúde mental.

Entende-se que saúde, de uma forma ampla, se refere ao bem-estar físico, mental, social, espiritual e ecológico do sujeito individual assim como do sujeito coletivo, por ver o indivíduo como sujeito da realidade, cidadão capaz de aprender a cuidar da sua saúde e da saúde dos outros (Góis, 2008) e como aquele que "não só age sobre o mundo, mas no cotidiano ..." (Campos, 2008, p. 58). Isso implica o trabalho conjunto dos profissionais e da comunidade, e, sem dúvida, a Psicologia se mostra intimamente ligada a esse conceito, mas, como disciplina, demorou muito para fazer parte da área da saúde, por isso, ainda busca definir seu campo de atuação e também sua contribuição teórica.

O campo de atuação da Psicologia na área da saúde tem-se resumido a atividades clínicas em consultório particular, através da atuação como profissional autônomo com uma clientela restrita e de poder aquisitivo diferenciado. Quando inserido nos serviços de saúde, seja nas atividades hospitalares, seja nos ambulatórios de saúde mental, o psicólogo tem sido considerado facilitador do processo de tratamento na preparação do paciente para cirurgias ou para outras intervenções apoiando-o na sua parte emocional, mas sempre no papel de agente passivo (Spink, 1992).

Mudanças na rotina hospitalar e a extensão dos serviços de saúde mental na rede básica propiciaram a inserção do profissional da Psicologia nas novas equipes de saúde, embora os estudos realizados por Spink (1985) explicitem as dificuldades com que o psicólogo teve que se deparar ao ingressar na atenção básica. A atuação desse profissional 
não condizia com sua formação, e muitos deles revelaram estar perdidos e não saber como atuar com a comunidade, com os usuários e com os outros profissionais, dificuldades essas que ainda estão presentes nos relatos dos profissionais da Psicologia, mas que vão sendo superadas com a prática. Essa superação pode ser percebida através dos espaços conquistados, dos recursos criados, da sua participação cada vez menos passiva e da valorização da sua presença dentro da área da saúde, no serviço, na academia e na pesquisa.

A entrada do psicólogo na implantação dos programas de saúde tem oferecido importantes contribuições relacionadas com o treinamento de recursos humanos, incorporando não só o usuário mas também os prestadores de serviço nos programas de promoção e prevenção da saúde e no próprio processo de saúde-doença, bem como na pesquisa em saúde. Percebe-se uma importante multiplicação de revistas especializadas na área da Psicologia da saúde, na organização de associações e de congressos e um aumento significativo da participação do psicólogo nos serviços de saúde, no atendimento direto ao usuário, na área social, nas atividades de docência e na pesquisa (Spink, 1992; Dimenstein, 1998).

No entanto, a constituição de um novo campo de saber, na prática, trouxe igualmente alguns problemas relacionados com as bases teóricas da Psicologia predominantemente psicodinâmica, com ênfase na clínica, na saúde mental, e uma total ausência de temas de saúde pública. Embora a Psicologia ocupe um lugar relevante entre as profissões da área da saúde, a discussão relativa à estrutura dos serviços de saúde, das políticas públicas, da saúde coletiva ou da saúde pública é ignorada nos cursos básicos ou não lhe é dada a devida importância (Nader, 1990 citado em Barros \& Yamamoto, 2002; Spink, 1992; Dimesntein, 1998 ).

\section{A inclusão da saúde coletiva na sala de aula: relato de experiência}

Este relato surge a partir da introdução da saúde coletiva na reformulação do currículo do curso de Psicologia. Este artigo tem como objetivo descrever a vivência de três anos como docente da disciplina Terapia Comunitária, dentro do eixo Práticas Psicológicas I e, ao mesmo tempo, refletir sobre a prática em sala de aula e no estágio de saúde coletiva discutindo as contribuições da terapia comunitária - TC como instrumento de sensibilização para o trabalho comunitário.

Como docente da área da saúde coletiva no curso de Psicologia, foi possível corroborar a visão relativa aos conteúdos dessa área, que era avaliada pelos docentes e pelos próprios estudantes como um tema pouco interessante, complicado, dispendioso e com resultados pouco proveitosos. Observou-se que a expectativa dos estudantes em relação ao conteúdo é que este deveria ser dado de maneira rápida, sem demandar muito envolvimento. Essa postura se refletia também no estágio, que, na maioria das vezes, deixava a desejar pela pequena dedicação dos estudantes e dos próprios professores. Além disso, a saúde coletiva tinha que competir com a grande valorização dada ao estágio clínico, cujo conteúdo e carga horária eram maiores em todos os currículos independentemente da abordagem, tanto em termos teóricos quanto práticos.

O interesse pelas discussões relacionadas com a saúde pública era baixo, e os estudantes apresentavam-se apáticos, não se envolviam nas reflexões, consideravam as leituras difíceis e manifestavam não ter pretensão de atuar nessa área. Pensar sobre o cuidado da saúde das comunidades não era o seu objetivo, porque este não condizia com o ideário de ser psicólogo, o que talvez explicasse seu 
desinteresse ao iniciar o estudo da disciplina. O objetivo principal, para eles, era a clínica através da atuação em consultório, afinal, o formando assim planeja, pois isso parece ser o que se espera dele socialmente. A imagem de psicólogo clínico se conserva e se sustenta na formação dos alunos através da valorização que os próprios docentes demonstram nas salas de aula. Por outro lado, o trabalho na atenção básica e o atendimento direto à comunidade são desvalorizados pelos próprios docentes, que não abrem mão da clínica, acreditando que esta seja a principal atuação do psicólogo.

Na reformulação do currículo, no ano 2005, além da implantação das Diretrizes Curriculares Nacionais, em 2004, teve grande influência a mudança de diretoria do curso. Essa nova gestão trouxe a saúde coletiva como uma das suas principais propostas, sendo incluídas disciplinas com conteúdos específicos da área de saúde coletiva. Essa inclusão despertou, e ainda desperta, grande resistência por parte de alguns docentes dessa faculdade, como se pode observar nos relatos de alguns professores:

O curso está perdendo seriedade, está sendo dada demasiada ênfase na saúde pública, o que vai terminar, dando ao curso um caráter de técnico... o tempo dedicado a essas aulas ou estágios deveria ser dedicado ao atendimento clínico, a aprender formas de psicoterapia mais eficientes, que perder o tempo com as comunidades... os alunos não gostam de ter que ir aos postos de saúde e não fazer nada... ficam em grupos e só, esperam cumprir a carga horária do estágio, pouco se envolvem com as atividades do serviço, não veem a hora de começar o estágio clínico... (reunião de professores, novembro de 2005).

Tais observações são lamentáveis e dificultam ainda mais a mudança de perfil do psicólogo e a de temas mais amplos que deem conta do preparo desse profissional para os novos campos de trabalho. É lamentável que isso ocorra, já que, há algumas décadas, a Psicologia é parte da saúde coletiva, e atuar nessa área exige que a formação dos futuros psicólogos a contemple, a compreenda, a teorize e a enriqueça com sua prática.

Como já foi apontado por Spink (1992), Silva (1992) e Dimenstein (1998), na prática da Psicologia, predomina a visão de que o indivíduo é desvinculado do seu contexto social. Ele é um ser abstrato e a-histórico; também na formação do psicólogo não é frequente a discussão de temas mais amplos, que permitam refletir sobre outros determinantes que interferem nos fenômenos psicológicos, tais como: fatores sociais, econômicos, culturais, espirituais e ambientais. O que se observa é uma discussão focada em categorias de classe, o que reduz o fenômeno social a uma unidade do tema, apenas, e não contribui com a compreensão do aspecto social como fator determinante do processo de adoecer na população que demanda o serviço.

Nas unidades básicas de saúde onde o profissional da Psicologia atua, sua prática está direcionada prioritariamente para o atendimento clínico, com pequena participação em atividades coletivas. A grande demanda da comunidade pelo atendimento psicológico tem gerado um impasse no serviço, mesmo porque o tempo disponível do psicólogo para o atendimento individual não cobre a demanda. Quando o usuário do Sistema Único de Saúde (SUS) procura atendimento, a lista de espera é tão grande que ele tem que aguardar na fila por muito tempo até ser liberada uma vaga. Isso provoca um aumento na demanda, pois o atendimento individual fica preso a um número determinado de sessões, de acordo com o problema do usuário (paciente), o que, necessariamente, diminui a oferta e gera uma necessidade de atendimento em saúde da população que o serviço não pode absorver. 
A isso se soma a hegemonia do profissional médico como autoridade na relação com o paciente. A forma como o psicólogo é inserido no setor da saúde, subordinado ao médico e sem autonomia, faz com que pouco se motive a atuar de forma independente dentro da atenção primária; sua prática fica restrita aos encaminhamentos do profissional médico, que dá pouco valor à sua intervenção. Também não é rara a visão que os outros profissionais da equipe têm quanto ao trabalho do psicólogo dentro da unidade. Ele é visto como aquele que pouco contribui, que pouco atende e que não dá conta da demanda, além do fato de que alguns profissionais se apropriam do saber da Psicologia, dispensando o saber do profissional formado na área.

Dimenstein (1998) já apontava algumas dificuldades desse profissional no serviço que ainda hoje persistem apesar das mudanças nas políticas e do incentivo ao trabalho coletivo na atenção primária. Essas dificuldades se caracterizam pela reduzida procura espontânea da população, pelo abandono do tratamento, logo nos primeiros encontros, pela falta de adesão dos pacientes aos programas criados pelo setor, pelo grande número de faltas, atrasos, agenda lotada, falta de vaga para o atendimento individual, carga horária reduzida para a demanda recebida, dificuldade de inserção dos psicólogos nas equipes multiprofissionais, defasagem salarial, instalações físicas precárias e falta de material e de apoio institucional. Tais barreiras têm gerado mal-estar entre os psicólogos e pouco os motivam a se envolver em projetos mais amplos que contribuam com o resgate da cidadania e/ou práticas mais solidárias e eticamente humanas.

Benevides (2005) afirma que a Psicologia manifesta pequeno interesse pela saúde pública e pela inserção do trabalho do psicólogo no debate sobre novos modos de intervenção, além dos enquadres clássicos da clínica individual e privada. Talvez por isso esse profissional não tenha conseguido sair do consultório para atuar no nível comunitário. A autora afirma que cuidar do indivíduo é, por si só, emancipador, quando voltado para a área social, para a comunidade. Mas o que se observa na prática do psicólogo na saúde pública é a continuidade da clínica, sem dar conta da demanda da comunidade.

A literatura acerca da atuação do psicólogo aponta como fator determinante para a sua atuação descontextualizada e, por sua vez, inadequada, a transposição do modelo hegemônico da clínica para o setor público, independentemente dos objetivos do setor onde atua na área da saúde pública, seja em unidades básicas de saúde, seja em centros ou ambulatórios, desconsiderando as características do serviço e da população por ele atendida. De acordo com Silva (1992) e Dimenstein (1998), a formação do profissional de Psicologia prioriza praticamente um único modelo de atendimento, o clínico, sendo este equivocadamente ampliado para a população que frequenta as unidades de saúde.

As ciências sociais vieram contribuir com a consciência social, mas, para isso, foram necessários vários momentos e décadas até que se fortalecessem. No caso da Psicologia, apesar de estarem mostrando maior interesse na elaboração de práticas mais comunitárias, que envolvam maior número de usuários e maior participação nas equipes e nos programas de promoção e prevenção em saúde, ainda há um longo caminho para o aumento de sua contribuição no processo saúde-doença (Spink, 1992; Silva; 1992, 2002).

Observa-se também maior envolvimento dos Conselhos Federais e Regionais de Psicologia (CFP e CRP), valorizando e ressaltando o papel do psicólogo na saúde pública e promovendo movimentos e fóruns de 
discussão que aos poucos vão conquistando o interesse de alguns profissionais da Psicologia em participar, se especializar e se envolver nessas práticas. Como exemplo, temos a atuação do psicólogo no Núcleo de Apoio à Saúde da Família (NASF), no apoio ao cuidado dos portadores de sofrimento mental e dos seus familiares, nas equipes de saúde da família, com a ampliação do atendimento a idosos, usuários de drogas, crianças, adolescentes, mulheres vítimas de violência e grupos vulneráveis. Ao mesmo tempo, o psicólogo compartilha seu saber com outros profissionais e com a comunidade (CFP, 2009). Mesmo assim, é necessário considerar que o trabalho na saúde pública demanda uma atuação mais complexa e mais ampla, e ainda não se conta com profissionais capacitados e sintonizados com os princípios do SUS, que é a atenção à saúde com que contam as comunidades (Dimenstein, 2009).

Com a participação ativa da Psicologia nas práticas de atenção à comunidade, a Psicologia tem contribuído de forma positiva em todos os programas da atenção básica com novos olhares sobre o comportamento e a personalidade dos usuários, com novas formas de promover educação e com terapêuticas direcionadas ao cuidado integral do indivíduo e da comunidade, priorizando a área social e a prática coletiva e grupal nas questões da saúde (Góis, 2008; Campos, 1996).

A prática psicológica tem contribuído para a compreensão da doença como fenômeno coletivo, para a construção e a valorização do saber das pessoas, a busca por alternativas terapêuticas ou espaços de cuidado, a busca pela superação de enfoques mais individualistas e a adoção de perspectivas mais amplas, globais e dinâmicas que compreendam a saúde e a doença dentro de um contexto histórico multideterminado; tem permitido também a interface entre o saber científico e o saber popular sobre a saúde e a doença em determinados grupos e discutido a imposição do saber reconhecido em detrimento do saber da comunidade (Dimenstein, 1998).

Para Silva (1992), as discussões sobre o papel do psicólogo em relação aos diferentes níveis de atenção na saúde pública foram recentes, a partir da década de 90 . Segundo a autora, essas discussões anteriormente eram centradas na saúde mental; no entanto, ainda se manifestam na pauta de encontros, seminários e fóruns, entre outros, apesar da abertura de mercado para o psicólogo, possibilitado pelas políticas públicas de saúde no serviço de atendimento comunitário.

Avaliar a atuação do psicólogo nas Unidades Básicas de Saúde, ou seja, nas instituições públicas de saúde destinadas à Atenção Primária à Saúde, não é uma tarefa simples. O tempo de inserção desse profissional nas instituições públicas de saúde é relativamente pequeno; há um contingente reduzido de profissionais atuando na área - apesar de vir aumentando gradativamente. Esse aumento na inserção do psicólogo na saúde pública requer pesquisas que permitam observar $\mathrm{o}$ impacto das suas práticas nesse novo campo de trabalho.

As dificuldades apontadas na atuação do psicólogo na saúde pública, como já foi colocado anteriormente, estão relacionadas à inadequação da sua formação acadêmica para o trabalho nos SUS, ao modelo limitado da sua atuação, e acrescenta-se a isso a dificuldade para adaptar-se ao perfil profissional exigido pela área.

Dimenstein (2009) continua afirmando que as propostas de um trabalho mais contextualizado, próximo das comunidades e executado por equipes multiprofissionais ainda está longe de se tornar um modelo dominante, pois requerem, segundo a autora, mudanças na formação acadêmica dos 
profissionais e na gestão do setor público, que ainda, apesar dos discursos, encontrase norteada por visões pouco participativas. O campo de atuação nos serviços públicos de saúde demanda novas habilidades dos profissionais, e a universidade continua formando pessoas despreparadas para as demandas na atenção básica.

Nesse contexto, os cursos de graduação têm um papel fundamental na determinação de modelos de atuação, que, para a prática na saúde pública, se tornam limitados e inadequados à realidade do País. Esses modelos valorizam o psicólogo como profissional liberal, o que não condiz com a atuação esperada no serviço de atendimento público (Silva, 1992; Dimenstein, 1998).

Um dos grandes desafios que o psicólogo enfrenta atualmente no campo da assistência pública à saúde é saber como agir de forma interdisciplinar, buscando alternativas para os problemas de saúde da população, o que implica a substituição do paradigma da clínica pelo da saúde pública; isso requer um novo modelo de atenção à saúde e de relação com o usuário bem como um modo sempre dinâmico de fazer saúde, tal como apontou Campos (1996), com base nas prioridades de saúde da população.

Para Dimenstein (2009), é preciso lembrar que muitos profissionais na área da saúde pública não percebem a inadequação de suas práticas e acreditam estar fazendo o que é correto. Mas aqueles que o percebem atribuem a questão à falta de recursos e ao autoritarismo da gestão, e a maioria entra em uma rotina de trabalho em que se reproduzem práticas que fazem parte do perfil convencional.

A participação do psicólogo na atenção primária, por exemplo, implica uma preparação para esse novo campo de trabalho, novo porque, mesmo estando presente na atenção básica, a sua ação tem sido fundamentalmente clínica e pouco comunitária, entendendo-se que a ação comunitária, segundo Góis (2008), é uma atividade prática e coletiva realizada dentro da comunidade, focada no potencial da comunidade, com estratégias de serviço dirigidas a grande número de pessoas, que prioriza a promoção e a prevenção através de ações educativas, de acordo com as necessidades, e cuja responsabilidade é compartilhada entre a comunidade e os profissionais da saúde. Para Campos (2000), não é possível considerar práticas dos psicólogos que não estejam comprometidas com o mundo, com o país em que vivemos, com as condições de vida da população e com o engajamento na produção de saúde.

Para Benevides (2005), a Psicologia é um campo de saber voltado para a subjetividade, e, se entendida como processo coletivo, não se pode separar a clínica da política, o individual do social, o singular do coletivo, os modos de cuidar dos modos de gerir, assim como a visão do macro e do micro. É no método, no modo de operar, que pode residir a maior contribuição da Psicologia para a saúde pública, o que constitui, indiscutivelmente, um grande desafio para a área. Avaliar as interfaces entre a Psicologia e o Sistema Único de Saúde (SUS) revestese de extrema importância; problematizar o que esse profissional pode fazer, o que quer fazer e o que efetivamente faz para construir outro mundo possível e, nele, outra saúde possível, se faz relevante para essa autora.

Ao se fomentar uma nova política de saúde, abrem-se campos de trabalho para a Psicologia, que passa a problematizar a aplicação de práticas tradicionais em novos cenários de atuação, o que implica, necessariamente, a construção de outras ferramentas de intervenção mais apropriadas para a efetiva inserção no trabalho na saúde pública. 
A Psicologia, ao atuar na saúde, segundo Borges e Cardoso (2005), deve inserir, nos seus pressupostos, uma intervenção mais local e coletiva, desenvolver um importante campo de conhecimentos, práticas e saberes para construir formas diferenciadas de intervenção, o que, necessariamente, deverá levá-la a buscar uma assistência menos tecnicista e mais humanizada, em uma composição de saberes e fazeres.

Como foi pontuado anteriormente, o processo saúde-doença inclui tanto a dimensão coletiva quanto a individual; coletiva, porque a saúde dos sujeitos é influenciada pela saúde do contexto social no qual estão inseridos, e individual, porque o sofrimento e o adoecimento, mesmo que possam ser compartilhados com outras pessoas, constituem uma experiência única, pessoal e singular (Sluzki, 1997; Lacerda \& Valla, 2004).

O sujeito busca alívio ou cura para seu sofrimento nos profissionais de saúde. Mas esses profissionais não são preparados para lidar com essas questões, devido ao fato de o tema do sofrimento ser pouco discutido na própria formação acadêmica, já que sua base é o modelo biomédico, que orienta de forma significativa as práticas de saúde, pautadas no diagnóstico e no tratamento de doenças definidas. Essa orientação limita os profissionais da saúde para lidar com o sofrimento e com os aspectos subjetivos do adoecer, sendo que, nos serviços, cada vez mais se evidenciam síndromes indefinidas como: ansiedade, estresse, angústias, depressão, medos e dores inespecíficas, entre outras, que não configuram doenças (Lacerna \& Valla, 2004).

\section{A terapia comunitária}

A terapia comunitária (TC) vem ao encontro da necessidade do profissional da saúde, oferecendo-lhe um instrumento de trabalho de promoção e prevenção em saúde que Ihe permite superar a técnica e perceber o homem em seu sofrimento em uma rede relacional, identificando não só a patologia mas também trabalhando o potencial das pessoas que se encontram em sofrimento. Ao mesmo tempo, possibilita-lhe fazer da promoção e da prevenção meta constante e tarefa de todos (Barreto, 2005).

A TC foi criada pelo prof. Dr. Adalberto Barreto a partir da sua experiência no atendimento de saúde mental na comunidade, na disciplina Antropologia da Saúde. Seu objetivo foi sensibilizar os futuros médicos em relação à riqueza da cultura dos povos e do perigo de a Medicina excluir não só o paciente mas também o próprio médico. Desde 1983, Barreto desenvolve um programa de pesquisa e educação comunitária, e a experiência com esse programa levou-o a desenvolver um trabalho na favela do Pirambu, em Fortaleza: o Projeto Quatro Varas. Diante da demanda progressiva do atendimento no Hospital Universitário, decidiu, com seus alunos, realizar um trabalho de prevenção e de cuidados psicológicos para as pessoas que vivem nesse lugar, criando o Movimento Integrado de Saúde Mental Comunitária e, em consequência, a terapia comunitária - TC (Barreto, 2005).

A TC tem construído seus alicerces a partir de cinco eixos teóricos, a saber: o pensamento sistêmico, a teoria da comunicação, a Antropologia cultural, a pedagogia de Paulo Freire e a resiliência. Na proposta, procura adaptar conceitos teóricos a uma linguagem coerente com as necessidades e realidades culturais das comunidades, e carateriza-se por ser um grupo de ajuda mútua, um espaço da palavra, da escuta e da construção de vínculos, com o objetivo de oferecer apoio aos indivíduos e famílias que vivem em situação de estresse e sofrimento psíquico. $\mathrm{Na}$ intervenção, o terapeuta comunitário tenta articular as dimensões biológica, 
social e política dos problemas e apoiar-se na competência, e não na carência dos indivíduos; toma como ponto de partida uma situação-problema, apresentada por alguém da comunidade e escolhida pelo grupo, e, a partir daí, dentro de um processo de questionamento, busca estimular e favorecer o crescimento do indivíduo e das pessoas para adquirir maior grau de autonomia, consciência e corresponsabilidade (Barreto, 2005).

Entende-se a terapia não como tratamento, mas em seu significado original, que é acolher, ser caloroso, cuidar, servir e atender, ao mesmo tempo em que parte da convicção de que, nas comunidades, o que as pessoas têm em comum, entre outras afinidades, é o sofrimento, a busca de soluções e a superação das suas dificuldades.

A terapia comunitária tem como objetivos reforçar a dinâmica interna de cada indivíduo, a autoestima individual e coletiva, a confiança em si mesmo, a valorização do papel da família e do grupo social e suscitar a união e a identificação com os valores culturais, além de favorecer a construção e a reconstrução das relações sociais e de promover e valorizar as instituições e práticas culturais tradicionais, bem como estimular a participação, promovendo o dialogo e a reflexão (Barreto, 2005).

Esse tipo de terapia favorece a formação de um espaço onde se procura compartilhar experiências de vida e sabedorias de forma horizontal e circular, que aquecem e fortalecem as relações humanas na construção de redes de apoio social, e ajuda a perceber que a força da comunidade está onde, muitas vezes, a família e a política não conseguem ser bem-sucedidas, e valoriza o poder do coletivo e suas interações no compartilhar, nas identificações com o outro e no respeito às diferenças (Barreto, 2005).
Por tanto, a terapia comunitária traz um novo olhar para o psicólogo, porque o coloca frente a uma realidade totalmente diferente daquela percebida na sua formação ou dentro do seu consultório, permitindo-lhe uma nova leitura sobre o sofrimento.

\section{Reflexões sobre a experiência na disciplina}

Refletir sobre a experiência de três anos da terapia comunitária dentro do curso de Psicologia foi o objetivo deste trabalho. Na reformulação do currículo, dentro do projeto pedagógico do curso de Psicologia, na unidade temática Práticas Psicológicas I, foi possível incluir o conteúdo da terapia comunitária a partir do $2^{\circ}$ semestre de 2005 , com a finalidade de oferecer aos estudantes uma perspectiva diferente da promoção e da prevenção em saúde nas comunidades, o que fortaleceu e promoveu o debate sobre a saúde coletiva dentro da formação do psicólogo.

Organizou-se um eixo temático de 60 horasaula teóricas no quinto (5을 semestre, sendo que, dentro das atividades da disciplina, foram incluídas dinâmicas de sensibilização e vivência da terapia comunitária em sala de aula. No sexto (6을 semestre, houve 80 horasaula, o que corresponde a 40 horas de estágio nos locais da comunidade onde se realizava a terapia comunitária, e 40 horas de supervisão. Os grupos de TC funcionavam em UBS, CAPS, associações, igrejas, centros comunitários, escolas, hospital, abrigos, casa de reeducação, creche comunitária e fazendinhas, entre outras. O responsável pelos grupos era um terapeuta comunitário, entre eles, a professora da disciplina e 21 psicólogos da rede municipal de saúde, formados no curso de aprimoramento em terapia comunitária. Os alunos eram distribuídos nos grupos de TC em duplas, e, dentro de suas atividades, estava a preparação do grupo (aquecimento) e a coterapia. 
A supervisão acontecia uma vez por semana na sala de aula, em pequenos grupos. Nesses encontros, os estudantes socializavam dúvidas, situações marcantes, dificuldades, conquistas e aprendizados, entre outras questões; socializavam-se também ferramentas (aquecimentos, músicas) e formas de superar as dificuldades como terapeutas. Discutiam-se as situações vivenciadas na prática à luz das diferentes teorias e inclusive buscando novos fundamentos teóricos e ferramentas que contribuíssem para o aprimoramento da terapia comunitária.

Após três anos de experiência na disciplina teórica e no estágio supervisionado, observaram-se algumas atitudes dos estudantes em relação aos novos conteúdos e à prática. No início das aulas, apresentavamse desconfiados com a nova proposta, que, de alguma forma, ia contra o que já lhes tinha sido passado durante a formação, relacionado com o poder que acreditam ter e que lhes é outorgado pelo conhecimento das teorias psicológicas. Quem sabe o que é melhor para o paciente é o psicólogo, e esse saber o qualifica para diagnosticar, nomear, interpretar e decidir sobre a patologia e o tratamento, definidos pelo saber científico, priorizando-se a patologia em detrimento do sujeito e de suas reais necessidades.

Nessa nova experiência, o estudante percebeu que não tem mais esse poder, logo, não é mais um salvador, e sim, um facilitador. Dentro da proposta da TC, o terapeuta é um instrumento do crescimento e do desenvolvimento humano e comunitário, portanto, deve ter sensibilidade para compreender o outro, saber escutar, estar consciente dos objetivos da TC e dos limites da sua intervenção. Seu papel, segundo Barreto (2005), não é resolver os problemas das pessoas, mas promover a socialização de experiências através da partilha e a criação de redes de apoio entre os participantes.
Como instrumento de construção de redes sociais solidárias de promoção da vida, o terapeuta deve mobilizar os recursos e as competências das pessoas, valorizando a diversidade cultural, possibilitando o empoderamento e a construção da cidadania. Conforme Barreto (2005, p.59), enquanto os modelos centram suas atenções na patologia, nas relações individuais, a TC convida a mudar o olhar, o enfoque, sem desqualificar as contribuições de outras abordagens; o que se propõe é ampliar seu ângulo de ação.

Na supervisão, é tarefa do supervisor sistematizar o trabalho, discutir os problemas e soluções e buscar meios para auxiliar os terapeutas, visando ao crescimento profissional e humano bem como à melhoria da qualidade de vida da população que participa desses encontros. Para entender o processo e auxiliar na orientação dos estudantes, foram registrados nos encontros de supervisão, pela própria supervisora, as vivências, dificuldades, preocupações, reflexões e discussões a partir da experiência na prática de TC. Essas anotações permitiram refletir e avaliar as contribuições desse instrumento, a TC, e a inclusão dos conteúdos da saúde coletiva na formação desses estudantes.

Compreender esse novo papel não foi fácil para os alunos, como pode ser visto nos seguintes depoimentos:

No início, tive dificuldades em aceitar que não poderia interpretar o que a pessoa estava falando; Trabalhar com a TC significa que devo esquecer todas as teorias que já aprendi...; Não entendo, durante todos os semestres, sempre nos foi falado que nossa atuação seria basicamente na clínica, e agora temos que atuar no coletivo, na saúde pública, fica difícil de compreender o porquê dessa mudança...; Não consigo imaginar como seria o trabalho 
comunitário, e muito menos, na terapia comunitária, que diz que a gente não pode falar para as pessoas o que elas devem fazer... então para que serve ter estudado as teorias da personalidade, as patologias e os testes psicológicos se não posso diagnosticar, nem interpretar? (anotações na supervisão).

O processo metodológico da disciplina Terapia Comunitária partiu do pressuposto de que a base do processo educativo deve estar sempre em permanente recriação dos conhecimentos. Para tanto, fez-se uso de instrumentos participativos que permitissem, de forma ordenada, progressiva, considerando o tempo dos estudantes, partir do seu saber, da sua vivência e do seu sentir e das diferentes situações e problemas que enfrentam na vida como seres sociais, e, a partir daí, desenvolver o processo de teorização da terapia comunitária.

As discussões e as vivências em sala de aula permitiram estabelecer relações entre a teoria e prática. Estabeleceu-se uma dinâmica na sala de aula que possibilitou, através da teorização, voltar à prática para discuti-la, analisá-la, melhorá-la e transformá-la, assim como regressar a ela com novos elementos que permitissem que o conhecimento inicial, a situação da qual partimos, fosse explicada e compreendida de forma integral e científica.

Nas aulas, os estudantes foram se identificando com os conteúdos teóricos relacionandoos com a prática, e desenvolveram uma postura crítica relativa ao uso das técnicas e à sua contribuição no desenvolvimento das comunidades:

No começo, tinha um pouco de resistência... (mesmo assim)... tentei abrir mais a minha mente e procurei ver os pontos positivos que com certeza são muitos; Apesar de não me identificar muito... acho a terapia comunitária muito importante e necessária... ajuda muitas pessoas (anotações na supervisão).

As diferentes técnicas utilizadas para desenvolver o conteúdo teórico da terapia comunitária e sensibilizar os estudantes para o trabalho coletivo potencializaram e enriqueceram o processo de aprendizagem; permitiram, também, o desenvolvimento de uma experiência de reflexão comum, em que todos foram partícipes da elaboração assim como das implicações desse processo, conforme pode ser observado nas declarações dos estudantes:

A disciplina contribuiu bastante com o meu crescimento pessoal; As teorias fizeram um exercício de reflexão muito grande em mim, o que me ajudou em diversos pontos; Passei a ler mais e entender o verdadeiro valor da terapia; Trouxe grandes contribuições para o meu eu; A disciplina despertou em mim um novo olhar para a comunidade, além de mudar a minha percepção sobre a necessidade do trabalho do psicólogo na saúde coletiva (anotações na supervisão).

Os alunos transformaram o conceito inicialmente formulado de sujeito, sensibilizaram-se com a dor e o sofrimento da comunidade, ressignificando seu próprio conceito de sofrimento, e impressionaramse com a transformação das pessoas e deles mesmos. O terapeuta, segundo Barreto (2005), deve identificar-se com o trabalho comunitário, estar aberto para a escuta atenta e afetuosa, acreditar no crescimento e nas potencialidades das pessoas, ser sensível e interagir com igualdade. Para Barreto, o perfil do terapeuta comunitário é semelhante ao papel de um educador, 
conforme é entendido por Paulo Freire; na prática educativa, as partes se assumem como seres sociais, que pensam, criam, se emocionam, se transformam com humildade e respeito mútuo. A terapia é uma ocasião para o terapeuta crescer com o grupo, desenvolver sua criatividade, descobrir novas técnicas e produzir novos conhecimentos. Nesse processo educativo, enquanto ensinamos, aprendemos, e, enquanto aprendemos, ensinamos (Freire, 1996), conforme é observado nos seguintes relatos: "A possibilidade de crescer enquanto o outro fala"; "Cresce dentro da gente as experiências dos outros"; "Contato com as minhas fraquezas"; "Vivência do não conhecido"; "Desenvolveu confiança, aprendi a falar"; "Calar para se escutar a si mesmo" (anotações na supervisão).

A discussão sobre o sofrimento e do adoecimento, segundo Lacerna e Valla (2004), implica compreender o processo de adoecimento além das suas causas; requer incluir a relação entre o sujeito e suas circunstâncias (contexto social) como determinantes das condições de saúde. Embora a desorganização social esteja presente no cotidiano da população, seu impacto nas condições de saúde não é o mesmo para todos os sujeitos. As diferentes formas como as pessoas reagem dependem da forma como elas se relacionam e da capacidade de lidar com as circunstancias sociais. A carência e a sensação de não ter controle sobre a vida e de não ter contatos sociais, sem dúvida, é forte influência na forma como se lida com o sofrimento.

As pessoas percebem e reagem de modo distinto aos eventos do cotidiano em função das características individuais e dos significados atribuídos às situações vivenciadas. É nesse sentido que determinados eventos de vida que são percebidos como situações estressantes para alguns sujeitos, capazes de desencadear sofrimento e adoecimento, podem não ter a mesma representação para outros (Sluzki, 1997).

Nos depoimentos dos estudantes, foi possível observar o impacto que possuem a vivência e a experiência com a terapia comunitária, tanto na sala de aula quanto na comunidade:

Perceber o grau dos problemas; Não tinha imaginado que as pessoas sofriam dessa forma; O quanto a gente fica longe das reais necessidades das pessoas; Impressiona como as pessoas conseguem superar as suas dificuldades; Chamou muito a atenção como as pessoas, mesmo no sofrimento e na carência, conseguem ser felizes (anotações na supervisão).

O modelo médico hegemônico vem orientar as práticas de saúde, pautado no diagnóstico e no tratamento de doenças já definidas, e nele existe pouco espaço para escuta dos sujeitos e de seus sofrimentos, para o acolhimento e para a atenção e o cuidado à saúde. Para Boff (2000), o cuidado faz parte da essência humana, e não é apenas um ato pontual, mas uma atitude de respeito, de preocupação e de responsabilização para com o próximo. Cuidar é, portanto, uma atitude interativa que inclui o envolvimento e o relacionamento entre as partes, compreendendo, acolhendo, escutando, respeitando o sofrimento e as histórias de vida. Se o cuidado pode diminuir o impacto do sofrimento, por outro lado, a sua falta pode agravá-lo e aumentar o isolamento social (Sluzki, 1997).

Na terapia comunitária, o estudante desenvolveu habilidades e competências para saber escutar, fazer silêncio, respeitar a história do outro, perceber que seu papel é de cuidador-educador e saber esperar o momento do outro, assim como pôde perceber que o processo de tratamento e cura pode ser consequência dessa dinâmica: 
"Sentia vontade de falar para a pessoa o que ela tinha que fazer, mas aprendi a esperar"; "Ouvir os problemas dos outros ajudou a ressignificar os meus" (anotações na supervisão).

Na prática, o estudante testou seus conhecimentos, aprendeu a valorizar o saber da comunidade, compreendeu a teoria na prática. A visão do atendimento individual, eminentemente clínico, passa para um trabalho mais coletivo. Os estudantes fizeram uma avaliação do significado dessa experiência para eles como pessoas e como profissionais da Psicologia. Entre os depoimentos, temos:

Na aula, a gente exercita a escuta; Não tinha dado tanta importância a parar e me ouvir a mim mesma; $A$ terapia comunitária foi um exercício que serviu mais para mim que para os outros; Ouvir a experiência da comunidade tem me ajudado a perceber o quanto as pessoas têm dentro delas a possibilidade de melhorar; eu não tinha enxergado isso, achava que eu tinha que ter todas as respostas; com a TC, percebi que não preciso, as respostas estão em cada um de nós (anotações na supervisão).

É preciso entender que a origem do sofrimento nem sempre é facilmente evidenciada e que, muitas vezes, o que o profissional acredita ser a fonte pode não corresponder à percepção do sujeito. Embora, segundo Barreto (2005), nem sempre seja possível curar os sujeitos, não se deve renunciar a cuidar deles e a dar-lhes apoio necessário no momento de crise: "O tempo todo na terapia estou aprendendo com a dor do outro"; "Percebi como as pessoas vão se transformando e como elas vão trazendo, nos seus depoimentos, as mudanças no cotidiano delas" (anotações na supervisão).

Os depoimentos dos estudantes, no final das aulas e do estágio, confirmaram que o conteúdo da terapia comunitária é um instrumento valioso que permite desmistificar o poder do profissional e desenvolver postura crítica mais humana e solidária, além de permitir ao psicólogo em formação ver-se como parte da comunidade, identificar-se com o sofrimento humano e rever o seu papel como pessoa e como profissional dentro de uma rede de relações.

Conforme o seguinte relato, o espaço continente favoreceu a troca de experiências entre os estudantes enriquecidas pelas contribuições dos que não tiveram a mesma experiência:

Posso dizer que essa disciplina mudou minha visão; como psicóloga, me colocou frente a frente com uma realidade que não conhecia, ampliou meu campo de visão sobre os outros, sobre meus próprios colegas, permitiu entrar em contato com meus colegas e não tinha valorizado a importância de parar para ouvir, o importante que foi para mim ser ouvida, res-significou o meu curso... (anotações na supervisão).

\section{Considerações finais}

Nesta experiência, ocorreram, no decorrer das aulas e dos encontros de supervisão, mudanças significativas no modo de entender as situações surgidas no estágio e na sala de aula quando se realizava a roda de terapia comunitária. As mudanças representaram um grande impacto nas atitudes dos estudantes e revelaram um grande amadurecimento do grupo nas discussões das experiências vivenciadas e na sua relação com os textos teóricos de apoio. 
Devemos estar cientes de que, em uma sala de aula, podemos não atingir todos os alunos, mas, nos depoimentos e na avaliação que fizeram da disciplina, foi possível perceber que pelo menos foi proveitosa para boa parte deles. O uso de estratégias diferenciadas e de uma concepção metodológica que deu sentido à experiência com o objetivo de transformar, desenvolver um pensamento e uma postura crítica pode ser um caminho que, sem dúvida, trará mudanças no fazer do profissional da saúde. A terapia comunitária mostrou ser um instrumento que pode contribuir para mudar e ampliar a visão do profissional diante da sua prática.

Como os diferentes autores citados neste texto colocaram, não há respostas prontas, mas elas irão aparecer na medida em que repensarmos nossos modelos de atuação e de formação. De alguma forma, através de encontros como os que aqui foram apontados, talvez se possa redimensionar o papel do psicólogo pela desinstitucionalização de saberes e práticas, do questionamento dos modelos instituídos que produzem um saber sobre o outro como instrumento de poder e controle social.

Se na formação forem criados espaços de sensibilidade que permitam o desenvolvimento de habilidades e competências através do contato com a realidade social, os profissionais terão maiores possibilidades de atuar, solicitando mudanças e requerendo modelos e conceitos mais amplos, que thes permitam reconhecer-se como trabalhadores da saúde, preocupados com a promoção do bem-estar da comunidade.

\section{Marta Fuentes-Rojas}

Doutorado em Saúde Coletiva Docente-pesquisadora Faculdade de Ciências Aplicadas Universidade Estadual de Campinas, São Paulo - SP - Brasil.

E-mail:marta.fuentes@fca.unicamp.br

Endereço para envio de correspondência:

Rua Engenheiro Humberto Soares de Camargo, 471 Cidade Universitária Campinas-SP CEP 13083-780

Recebido 14/11/2009, 1a Reformulação 5/11/2010, Aprovado 23/12/2010 
Barreto, A. de P. (2005). Terapia comunitária passo a passo. Fortaleza, CE: Gráfica LCR.

Barros, D. C., \& Yamamoto. O. H. (2002). Psicologia e políticas públicas de saúde: anotações para uma análise da experiência brasileira. Psicología para América Latina. Revista de la Unión Latinoamericana de Psicología. Recuperado em outubro de 2009 de www.psicolatina.org/00/saude.html.

Benevides, R. (2005, maio/ago.). A psicologia e o sistema único de saúde: quais interfaces? Psicologia \& Sociedade, 17(2), 21-25.

Boff, L. (2000). Saber cuidar: ética do humano - compaixão pela Terra. Petrópolis, RJ: Vozes.

Borges, C. C., \& Cardoso, C. L. (2005, maio/ago.). A psicologia e a estratégia saúde da família: compondo saberes e fazeres. Psicologia e Sociedade, 17(2), 26-32. Recuperado em 29 outubro de 2010 de < http://www.scielo.br/scielo.php?script=sci arttext\&pid $=$ S0102-71822005000200005\&lng $=$ pt\&nrm $=i$ so >. ISSN 0102-7182.

Campos, G. W. S. (2000). Um método para análise e co-gestão de coletivos - a construção do sujeito, a produção de valor de uso e a democracia em instituições: o método da roda. São Paulo: Hucitec.

Campos, G. W. S. (2006). Tratado de saúde coletiva. São Paulo: Hucitec; Rio de Janeiro: Editora Fiocruz.

Campos, R. H. de F. (1996). Introdução: a psicologia social comunitária. In R. H. de F. Campos (Org.), Psicologia social comunitária: da solidariedade à autonomia. Petrópolis, RJ: Vozes.

Conselho Federal de Psicologia. (2009). A prática da psicologia e o núcleo de apoio à saúde da família. Brasília, DF : Autor. Recuperado em 29 de outubro de 2010 de http://www.scribd. com/doc/36953954/A-pratica-da-Psicologia-e-o-Nucleo-deApoio-a-Saude-da-Familia.
Dimenstein, M. D. B. (2009, jun./jul.). Conversando com o psicólogo. Sem medo de repensar. Entrevista. Psi Jornal de Psicologia. CRP - SP, 18-19.

Dimenstein, M. D. B. (1998). O psicólogo nas unidades básicas de saúde: desafios para a formação e a atuação profissional. Estudos de Psicologia, 3(1), 53-81.

Freire, P. (1996). Pedagogia da autonomia: saberes necessários à prática educativa. São Paulo: Paz e Terra.

Góis, C. W. de L. (2008). Saúde comunitária: pensar e fazer. São Paulo: Aderaldo \& Rothschild.

Lacerna, A., \& Valla, V. V. (2004). As práticas terapêuticas de cuidado integral à saúde como proposta para aliviar o sofrimento. In R. Pinheiro, \& R. A. de Mattos (Orgs). Cuidado: as fronteiras da integralidade. Rio e Janeiro: Hucitec.

Silva, R. C. (1992). A formação do psicólogo para o trabalho na saúde pública. In F.C. B. Campos (Org.), Psicologia e saúde: repensando práticas (pp. 25-40). São Paulo: Hucitec.

Silva, R. C. (2002). Metodologias participativas para trabalhos de promoção de saúde e cidadania. São Paulo:Vetor.

Sluzki, C. E. (1997). A rede social na prática sistêmica. São Paulo: Casa do Psicólogo.

Spink, M. J. (1985). Regulamentação das profissões da saúde: o espaço de cada um. Cadernos Fundap, 5(10), 24-43.

Spink, M. J. P. (1992). Psicologia da saúde: a estruturação de um novo campo de saber. In F. C. B. Campos (Org.), Psicologia e saúde: repensando práticas. São Paulo: Hucitec. 